\title{
ATRIBUTOS QUÍMICOS DE UM LATOSSOLO DE CERRADO SOB PLANTIO DIRETO, DE ACORDO COM DOSES E FORMAS DE APLICAÇÃO DE CALCÁRIO(1)
}

\author{
Luis Reynaldo Ferracciu Alleoni ${ }^{(2)}$, Michel Alexandro \\ Cambri $^{(3)}$ \& Eduardo Favero Caires ${ }^{(4)}$
}

\begin{abstract}
RESUMO
Em áreas cultivadas em sistema plantio direto, a incorporação de calcário não é desejável. Com isso, o corretivo é aplicado sobre a superfície e concentrase nos primeiros centímetros do solo. Para avaliar a correção da acidez de camadas mais profundas do perfil, com o passar do tempo, estudou-se o efeito de doses de calcário dolomítico $\left(2,0,4,9\right.$ e 7,8 $\left.\mathrm{tha}^{-1}\right)$, aplicadas em superfície ou incorporadas, nos atributos químicos de um Latossolo Vermelho distrófico de cerrado. Amostras de terra foram coletadas nas profundidades de 0-5, 5-10, 1020 e $20-40 \mathrm{~cm}$, aos seis, 18 e 30 meses da aplicação do corretivo. Após seis meses, a calagem superficial promoveu aumento nos valores de $\mathrm{pH}$, na saturação por bases e nos teores de Ca e Mg trocáveis, bem como diminuição nos teores de $\mathrm{Al}$ trocável e da acidez potencial $(\mathrm{H}+\mathrm{Al}$ ) somente na camada de 0-5 cm. Aos 18 e 30 meses da aplicação do calcário, tais efeitos estenderam-se até $10 \mathrm{~cm}$. A incorporação do calcário proporcionou correção da acidez do solo até $20 \mathrm{~cm}$ de profundidade, a partir de seis meses após a sua aplicação. A calagem na superfície ou com incorporação não influenciou a correção da acidez do subsolo $(20-40 \mathrm{~cm})$. A saturação por bases na profundidade de $0-20 \mathrm{~cm}$ ficou abaixo da estimada pelo cálculo da dose do corretivo, mesmo com a incorporação do calcário, após 30 meses. A aplicação de calcário reduziu os teores de Mn e Fe no solo até à profundidade de $10 \mathrm{~cm}$, quando realizada na superfície, e até $20 \mathrm{~cm}$, quando incorporada, em conseqüência do aumento do $\mathrm{pH}$ proporcionado pela calagem. Mesmo assim, os teores de Mn e Fe no solo mantiveram-se acima dos limites considerados baixos.
\end{abstract}

Termos de indexação: acidez do solo, calcário dolomítico, modos de aplicação, lixiviação de íons.

\footnotetext{
(1) Parte da Tese de Mestrado do segundo autor, apresentada à Escola Superior de Agricultura "Luiz de Queiroz" - ESALQ/USP. Recebido para publicação em abril de 2004 e aprovado em agosto de 2005.

(2) Professor do Departamento de Solos e Nutrição de Plantas, Escola Superior de Agricultura "Luiz de Queiroz" - ESALQ/USP. Caixa Postal 9, CEP 13418-900 Piracicaba (SP). E-mail: lrfalleo@esalq.usp.br

(3) Engenheiro-Agrônomo, Doutor em Agronomia. Caixa Postal 39, CEP 68625-000 Paragominas (PA). E-mail: michel_cambri@yahoo.com.br

(4) Professor do Departamento de Ciência do Solo e Engenhearia Agrícola, Universidade Estadual de Ponta Grossa - UEPG. Campus de Uvaranas, CEP 84030-900 Ponta Grossa (PR) E-mail: efcaires@uepg.br
} 


\title{
SUMMARY: CHEMICAL ATTRIBUTES OF A CERRADO OXISOL UNDER NO-TILLAGE AS AFFECTED BY LIME APPLICATION METHODS AND DOSES
}

\begin{abstract}
Lime incorporation is not desirable in no-tillage systems. Lime is therefore applied on the soil surface, concentrating the product on the first few centimeters of the profile. We evaluated the aftereffects of dolomitic limestone (2.0, 4.9 and $7.8 \mathrm{t}$ ha-1) application, either on surface or incorporated, on the deeper layers of a Typic Haplustox from the Brazilian Cerrado. Soil samples were collected at six, 18 and 30 months after liming at depths of 0 5, 5-10, 10-20, and 20-40 cm. After six months the pH, base saturation (BS), and Ca and Mg concentration increased after surface liming, while both Al concentration and potential acidity $(H+A l)$ were reduced only down to $5 \mathrm{~cm}$. These effects extended down to $10 \mathrm{~cm}$ when evaluated at 18 and 30 months after liming. Lime incorporation decreased the soil acidity to a depth of up to $20 \mathrm{~cm}$ six months after the application. Surface or incorporated liming did not influence the soil acidity in the subsoil $(20-40 \mathrm{~cm})$. Base saturation at 0 $20 \mathrm{~cm}$ depth was lower than the estimated BS, even 30 months after liming. Manganese and Fe concentration decreased at $10 \mathrm{~cm}$ depth after surface liming and decreased at $20 \mathrm{~cm}$ after lime incorporation as a consequence of the $\mathrm{pH}$ increase. Still, the concentration of these micronutrients remained above the limit considered critical for plants.
\end{abstract}

Index terms: soil acidity, surface liming, application methods, ion leaching.

\section{INTRODUÇÃO}

A área cultivada no sistema plantio direto (SPD) vem aumentando significativamente no Brasil. Na safra de 2000/01, 17,4 milhões de hectares foram cultivados sob esse sistema, dos quais 4,9 milhões foram no cerrado (FEBRAPDP, 2003). A acidez é um dos maiores problemas encontrados na maioria dos solos brasileiros, especialmente na região do cerrado (Lopes, 1984). Há evidências de que a necessidade de calcário no sistema plantio direto seja menor do que no sistema convencional de preparo (Caires et al., 1998; 1999). Todavia, são poucas as informações a respeito dos efeitos da aplicação superficial de calcário em tal sistema de cultivo, nas características químicas do solo, principalmente em áreas de cerrado.

O calcário é um produto de baixa solubilidade, requerendo sua incorporação no solo para promover maior reação. Entretanto, a mobilização do solo para a incorporação de corretivos não é desejável no SPD, pois ela pode destruir atributos físicos favoráveis, do ponto de vista de conservação, obtidos ao longo do tempo de adoção do sistema (Amaral \& Anghinoni, 2001). São necessários, aproximadamente, três anos de SPD para a recuperação de 59 a $90 \%$ dos agregados destruídos pela mobilização do solo (Cargnelutti et al., 1996). Dessa forma, a prática da calagem em superfície no SPD mostra-se interessante do ponto de vista da conservação do solo.

Pesquisas realizadas com aplicação de calcário na superfície em solos brasileiros têm indicado aumentos de $\mathrm{pH}$ e dos teores de $\mathrm{Ca}$ e $\mathrm{Mg}$ trocáveis e redução do Al trocável até camadas de $20-40 \mathrm{~cm}$
(Oliveira \& Pavan, 1996; Caires et al., 1998; 2000) ou de 40-60 cm (Caires et al., 2001), em regiões sem problemas de limitação hídrica. Por outro lado, em um estudo de longo período realizado em solo australiano, em região com precipitação pluvial média de apenas $570 \mathrm{~mm}$ ao ano, foi verificado que a aplicação de calcário $\left(1,5 \mathrm{t} \mathrm{ha}^{-1}\right)$ sobre a superfície levou de dois a quatro anos para alcançar a profundidade de $10 \mathrm{~cm}$ e não foi eficiente em aumentar o $\mathrm{pH}$ abaixo dessa profundidade por um período de oito anos (Conyers et al., 2003). Isso mostra que o movimento de alcalinidade parece ser dependente da dose e do tipo de calcário aplicado na superfície, das propriedades físicas (teores de argila e porosidade) e de matéria orgânica do solo e do regime hídrico de cada região.

O conhecimento da dinâmica da correção da acidez a partir da superfície do solo no SPD, ao longo do tempo, é necessário para que possam ser estabelecidos ajustes na recomendação de calagem (doses e freqüência) (Amaral \& Anghinoni, 2001; Caires et al., 2005).

Assim, este trabalho teve o objetivo de avaliar os efeitos de doses de calcário, aplicadas em superfície e com incorporação, nos atributos químicos de um solo de cerrado aos seis, 18 e 30 meses da aplicação do corretivo.

\section{MATERIAL E MÉTODOS}

O estudo foi realizado com amostras de terra coletadas em Rondonópolis - MT (16 $6^{\circ} 55^{\prime} 51^{\prime \prime} \mathrm{S}$ e $54^{\circ} 47^{\prime} 52$ "W) em um Latossolo Vermelho 
distrófico textura muito argilosa, em área cultivada há 21 anos, sendo nove sob o SPD. Na instalação do experimento em 1999, o solo (camada de 0-20 cm) apresentava $\mathrm{pH}$ em $\mathrm{CaCl}_{2} 0,01 \mathrm{~mol} \mathrm{~L}^{-1} 4,4 ; 34 \mathrm{~g} \mathrm{dm}^{-3}$ de $\mathrm{MO} ; 30,9$ e $1,6 \mathrm{mmol}_{\mathrm{c}} \mathrm{dm}^{-3}$ de $\mathrm{Ca}, \mathrm{Mg}$ e $\mathrm{K}$, respectivamente; $3 \mathrm{mmol}_{\mathrm{c}} \mathrm{dm}^{-3}$ de Al trocável, CTC a pH 7,0 de 112,6 $\mathrm{mmol}_{\mathrm{c}} \mathrm{dm}^{-3}$; saturação por bases de $36 \%, 210,60$ e $730 \mathrm{~g} \mathrm{~kg}^{-1}$ de areia, silte e argila, respectivamente.

O delineamento experimental empregado foi em blocos casualizados com parcelas subdivididas, com quatro repetições. As parcelas foram constituídas de dois tratamentos: calcário aplicado superficialmente e calcário incorporado, e as subparcelas de três doses de calcário: 2,0, 4,9, 7,8 $\mathrm{t}_{\text {ha }}{ }^{-1}$, além da testemunha. As doses foram calculadas com o objetivo de elevar a saturação por bases a 50, 70 e 90 \%, respectivamente, de acordo com o método proposto por Raij et al. (1996).

Foi utilizado calcário dolomítico com 78,5\% de PRNT. A aplicação foi realizada manualmente, a lanço, na área total de cada subparcela, no mês de julho de 1999. A incorporação do calcário foi efetuada por meio de duas gradagens pesadas e duas gradagens niveladoras. Após a incorporação do calcário, as parcelas foram mantidas, durante quatro anos agrícolas, em SPD, sem revolvimento do solo. A aplicação superficial de calcário foi feita por cima dos restos vegetais do milheto (cultura de inverno). Foram retiradas amostras de terra de cada subparcela (formadas por quatro subamostras com cerca de $5 \mathrm{~cm}$ de espessura e $20 \mathrm{~cm}$ de largura, coletadas com pá de corte) das camadas de $0-5$, $5-10,10-20$ e $20-40 \mathrm{~cm}$ de profundidade, aos seis, 18 e 30 meses após a aplicação do calcário. A precipitação pluvial ocorrida do início do experimento até à ocasião de tais amostragens foi, respectivamente, de 762, 1456 e $1798 \mathrm{~mm}$.

$\mathrm{O} \mathrm{pH}$ foi obtido em $\mathrm{CaCl}_{2}$ 0,01 $\mathrm{mol} \mathrm{L}^{-1}$ (relação solo:solução 1:2,5), os teores de $\mathrm{Ca}, \mathrm{Mg}, \mathrm{K}$ e $\mathrm{P}$ no solo extraídos pela resina trocadora de íons, o $\mathrm{Al}$ extraído com $\mathrm{KCl} 1 \mathrm{~mol} \mathrm{~L}^{-1}$, enquanto a acidez potencial $(\mathrm{H}+\mathrm{Al})$ foi estimada pelo método do pH SMP (Camargo et al., 1986); com esses resultados, foram calculadas a CTC a $\mathrm{pH} 7,0$ e a saturação por bases (V \%). A matéria orgânica foi determinada após oxidação com dicromato de potássio em presença de ácido sulfúrico e titulação do excesso de dicromato com sulfato ferroso amoniacal (Camargo et al., 1986); o enxofre foi extraído com fosfato monocálcico (Vitti, 1989), e Cu, $\mathrm{Fe}, \mathrm{Mn}$ e Zn foram extraídos com DTPA-TEA pH 7,3 (Camargo et al., 1986). O boro foi extraído com água quente, usando aquecimento com forno de microondas (Abreu et al., 2001).

Os efeitos de modos de aplicação de calcário nos atributos químicos do solo foram avaliados pelo teste F. Foram feitas análises de regressão para doses de calcário aplicadas e interação entre modo de aplicação e doses.

\section{RESULTADOS E DISCUSSÃO}

A calagem aumentou o $\mathrm{pH}$, os teores de $\mathrm{Ca}$ e $\mathrm{Mg}$ trocáveis e a saturação por bases, bem como reduziu os teores de $\mathrm{Al}$ trocável e a acidez potencial $(\mathrm{H}+\mathrm{Al})$ do solo (Figuras 1 a 3). Na primeira época de amostragem (seis meses após a calagem), as modificações nesses atributos foram até à profundidade de $20 \mathrm{~cm}$, quando o calcário foi incorporado, enquanto ficaram restritas à camada de $0-5 \mathrm{~cm}$, quando o calcário foi aplicado em superfície. Nas outras duas épocas de amostragem (18 e 30 meses após a calagem), os efeitos foram observados até $20 \mathrm{~cm}$ de profundidade, nas parcelas com calcário incorporado, e até $10 \mathrm{~cm}$ de profundidade, quando a calagem foi realizada em superfície. A calagem na superfície proporcionou pequena diminuição no $\mathrm{Al}$ trocável da camada de solo de 10-20 cm 30 meses após a aplicação, mas devem-se considerar os baixos teores de Al trocável presentes no solo.

Percebeu-se uma frente de correção da acidez e migração de bases em profundidade, mesmo sem a incorporação do calcário, a qual foi mais pronunciada nas maiores doses e com o tempo após a aplicação. Apesar da alta dose de calcário $\left(7,8 \mathrm{t} \mathrm{ha}^{-1}\right)$, sem incorporação, a elevação do $\mathrm{pH}$ na camada de $0-5 \mathrm{~cm}$ não foi tão abrupta: ficou em torno de 6,0 , seis meses após a aplicação do calcário, e atingiu 6,3 , após 30 meses. Isso pode ser explicado pelo alto poder tampão existente nessa camada mais superficial, resultante do alto conteúdo de matéria orgânica (em torno de $\left.50 \mathrm{~g} \mathrm{~kg}^{-1}\right)$.

A neutralização da acidez do solo (Figura 1) e o aumento de Ca e Mg trocáveis (Figura 2) restringiramse aos primeiros $10 \mathrm{~cm}$ de profundidade, mesmo após 30 meses da aplicação do calcário em superfície, o que revela comportamento diferente em comparação com outros trabalhos realizados na região sul do Brasil. Oliveira \& Pavan (1996) obtiveram aumento de $\mathrm{pH}$ e diminuição da acidez trocável até $40 \mathrm{~cm}$ de profundidade após 32 meses da calagem superficial em um Latossolo Vermelho-Escuro argiloso.

Resultados semelhantes foram obtidos por Caires et al. (1998), em um Latossolo Vermelho distrófico textura média, com aumento do $\mathrm{pH}$ e diminuição da acidez trocável até $20 \mathrm{~cm}$, após 12 meses da calagem, chegando até $60 \mathrm{~cm}$, após 68 meses (Caires et al., 2001). Em um Latossolo Vermelho distrófico argiloso, Caires et al. (2002) observaram neutralização da acidez até $20 \mathrm{~cm}$ de profundidade, 23 meses após a calagem.

Apesar de a precipitação pluvial da região do presente trabalho (Rondonóplis, MT) ter sido semelhante à dos locais onde se desenvolveram os trabalhos do sul do País (cerca de $1.500 \mathrm{~mm}$ ao ano), deve-se considerar que o solo era de textura muito argilosa (730 $\mathrm{g} \mathrm{kg}^{-1}$ de argila na camada de $0-20 \mathrm{~cm}$ ), o que poderia explicar a menor movimentação do 

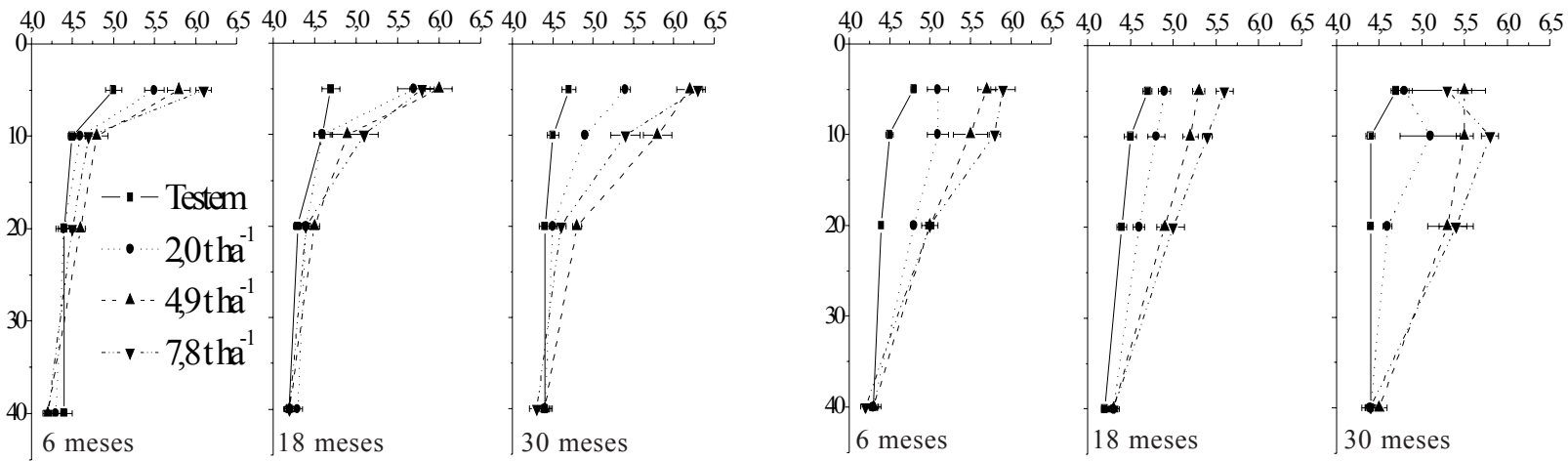

Al trocável $\left(\mathrm{mmol}_{\mathrm{c}} \mathrm{dm}^{-3}\right)$
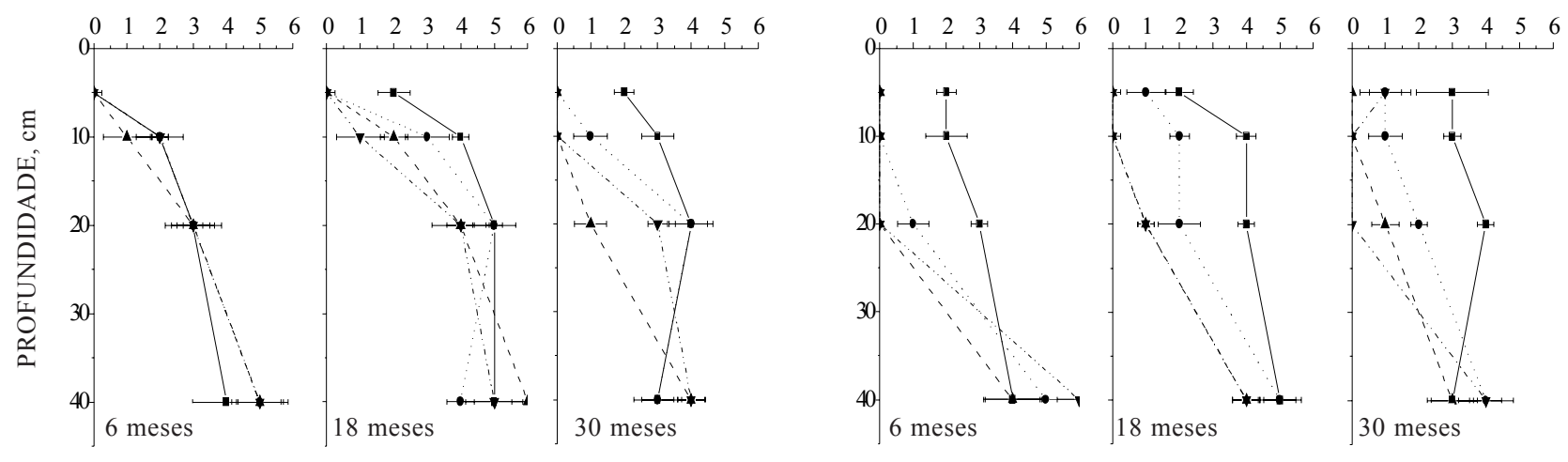

$\mathrm{H}+\mathrm{Al}\left(\mathrm{mmol}_{\mathrm{c}} \mathrm{dm}^{-3}\right)$
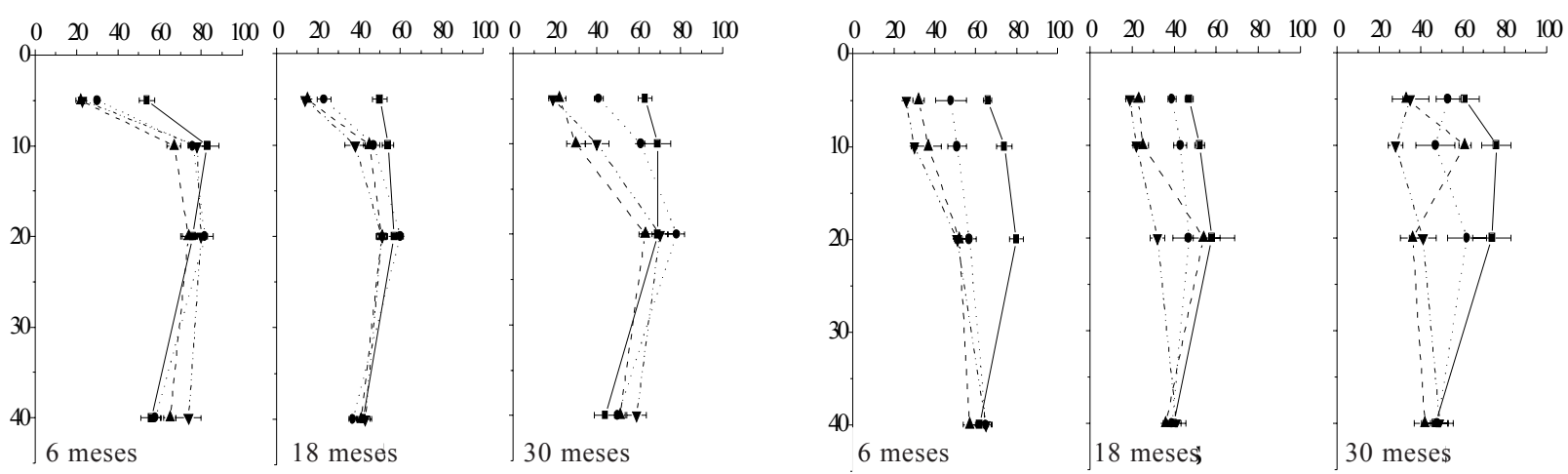

Figura 1. Efeito das doses de calcário, aplicado em superfície e incorporado, nos valores de $\mathbf{p H ~ e m ~} \mathrm{CaCl}_{2}$, Al trocável e acidez potencial $(\mathrm{H}+\mathrm{Al})$ em um Latossolo Vermelho distrófico, aos seis, 18 e 30 meses da aplicação do calcário, em diferentes profundidades. (Barras horizontais referem-se ao erro-padrão das médias).

calcário aplicado em superfície, com efeito semelhante na frente de alcalinização. A ação do calcário na neutralização da acidez de subsolos é dificultada pelo aumento da retenção de cátions que ocorre com a geração de cargas elétricas variáveis negativas com a elevação do $\mathrm{pH}$ do solo.

Além disso, ânions resultantes de sua dissolução, responsáveis pela correção da acidez, são também consumidos nas reações com outros cátions ácidos
$\left(\mathrm{Al}^{3+}, \mathrm{Mn}^{2+}\right.$ e $\left.\mathrm{Fe}^{2+}\right)$ na camada de deposição do calcário. No entanto, o aumento do $\mathrm{pH}$ na superfície do solo pode acelerar a velocidade com que o $\mathrm{HCO}_{3}{ }^{-}$, acompanhado por $\mathrm{Ca}$ e $\mathrm{Mg}$, movimenta-se para o subsolo para reagir com a acidez. Os efeitos da calagem em profundidade devem ocorrer somente quando o pH (em água), na zona de dissolução do calcário, atingir valores da ordem de 5,2 a 5,5 (Rheinheimer et al., 2000). 
Desta forma, considerando que a diferença entre o $\mathrm{pH}$ em $\mathrm{CaCl}_{2}$ e o $\mathrm{pH}$ em água seja, em média, de 0,6 unidade (Raij, 1991), é provável que ainda esteja ocorrendo migração dos ânions da dissolução do calcário para as camadas subsuperficiais de 5-10 e 10-20 cm, já que o pH nestas profundidades encontra-se acima da faixa encontrada por Rheinheimer et al. (2000), principalmente nas parcelas com maiores doses de calcário (4,9 e 7,8 t ha-1) (Figura 1).
No SPD, a manutenção de resíduos vegetais na superfície do solo diminui as variações de temperatura e de umidade do solo, o que favorece a fauna responsável pela abertura de canais contínuos, pelos quais pode ocorrer movimentação física do calcário aplicado superficialmente (Oliveira \& Pavan, 1996). Esses poros ou canais deixados pelas raízes mortas e o fendilhamento natural do solo favorecem o deslocamento de partículas finas, junto com o movimento descendente da água. O volume

\section{$\mathrm{Ca}\left(\mathrm{mmol}_{\mathrm{c}} \mathrm{dm}^{-3}\right)$}
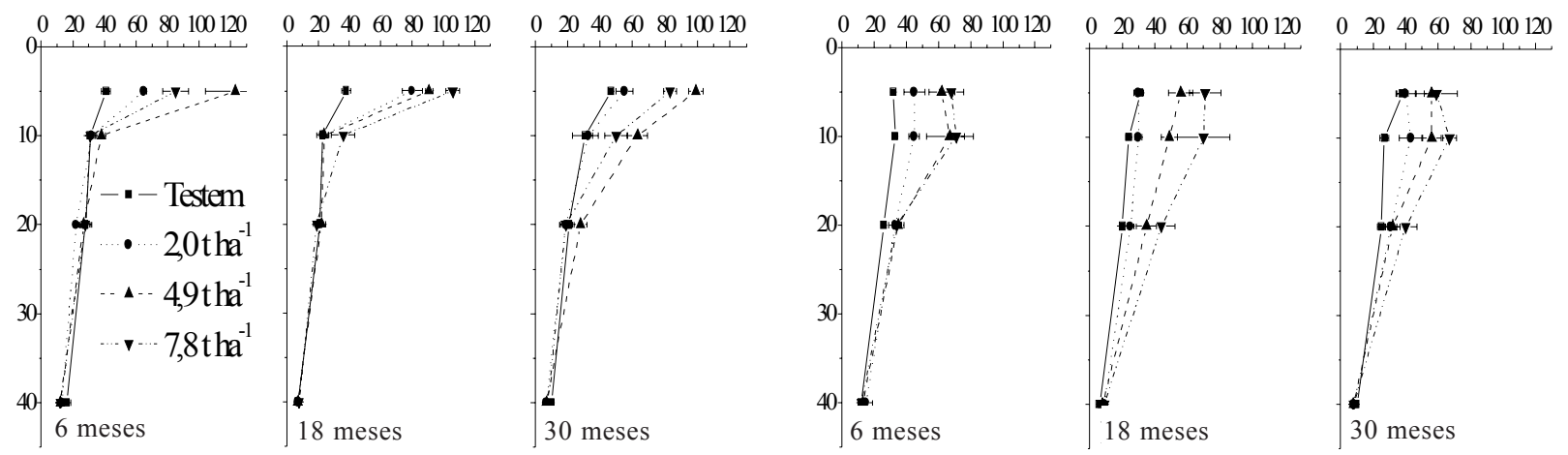

\section{$\operatorname{Mg}\left(\operatorname{mmol}_{\mathrm{c}} \mathrm{dm}^{-3}\right)$}
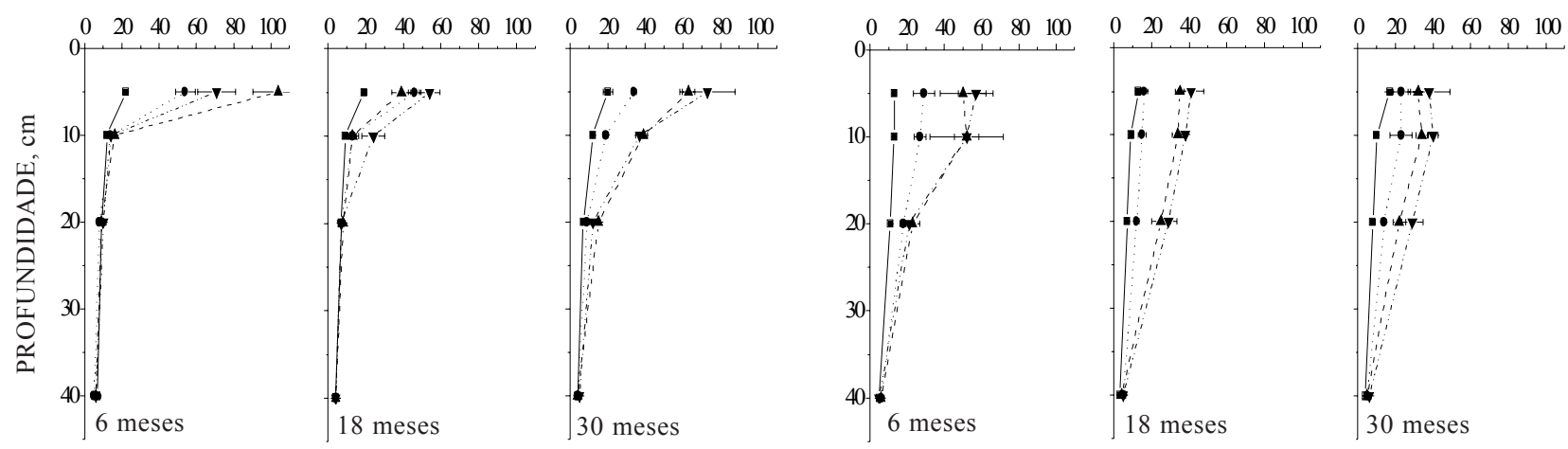

\section{$K\left(\operatorname{mmol}_{c} \mathrm{dm}^{-3}\right)$}
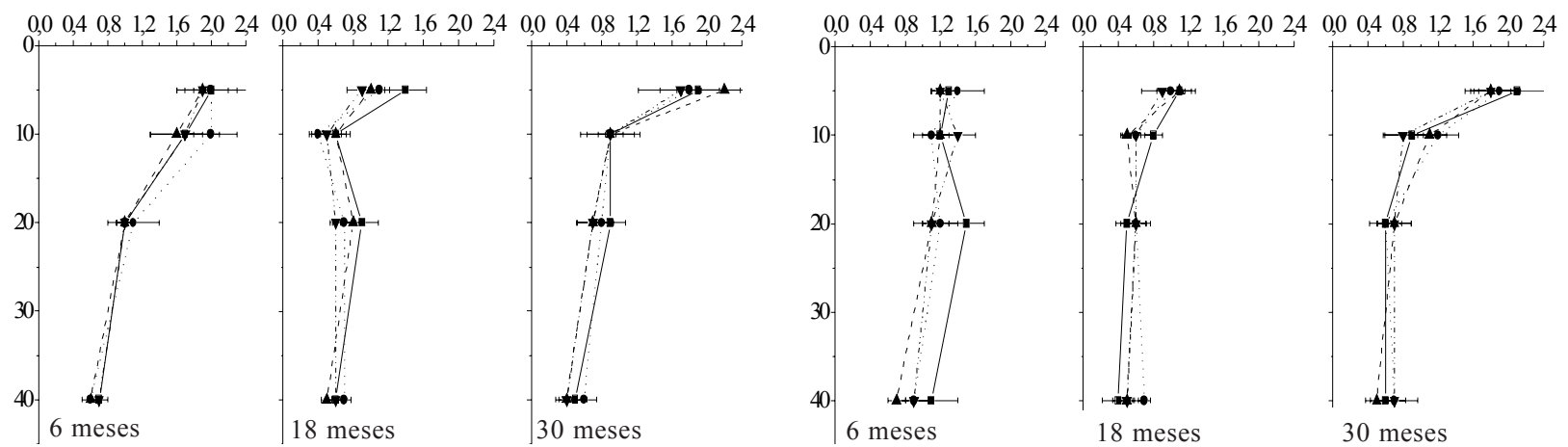

Figura 2. Efeito das doses de calcário, aplicado em superfície e incorporado, nos teores das bases Ca, Mg e K em um Latossolo Vermelho distrófico, aos seis, 18 e 30 meses da aplicação do calcário, em diferentes profundidades. (Barras horizontais referem-se ao erro-padrão das médias). 
de macroporos e a conexão entre eles é maior no SPD do que em sistemas que utilizam a mobilização do solo por grades ou arados (Schaefer et al., 2001). Mesmo assim, Petrere \& Anghinoni (2001), estudando a movimentação de calcário "filler" em colunas de solos sob SPD e sistema de plantio convencional (SPC), observaram que no SPD as taxas de infiltração foram maiores $\left(19\right.$ e $16 \mathrm{~cm} \mathrm{~h}^{-1}$, respectivamente, para o SPD e o SPC); porém a movimentação física do calcário ficou restrita aos primeiros centímetros do solo (camada de 2,5$3,75 \mathrm{~cm}$ ), nos quais foi observada a presença de dolomita.

A aplicação do calcário dolomítico, em superfície ou com incorporação, não alterou os teores de $\mathrm{K}$ trocável no solo em nenhuma das camadas estudadas (Figura 2). O teor de $\mathrm{K}$ foi influenciado pelo revolvimento do solo para a incorporação do calcário. Na ausência de calagem, seis meses após o revolvimento do solo, os teores de K trocável foram mais baixos nas camadas de $0-5 \mathrm{~cm} \quad(1,3$ e $2,0 \mathrm{mmol}_{\mathrm{c}} \mathrm{dm}^{-3}$, para os tratamentos com e sem revolvimento do solo, respectivamente) e $5-10 \mathrm{~cm}$ $\left(1,2\right.$ e $1,8 \mathrm{mmol}_{\mathrm{c}} \mathrm{dm}^{-3}$, para os tratamentos com e sem revolvimento do solo, respectivamente). Mesmo assim, 30 meses após o revolvimento, o gradiente de concentração de K trocável a partir da superfície do solo voltou a ser semelhante ao do solo não revolvido.

A calagem na superfície aumentou a CTC a $\mathrm{pH} 7,0$ do solo apenas na camada de $0-5 \mathrm{~cm}$ aos seis e 18 meses da aplicação do calcário, chegando a $10 \mathrm{~cm}$ de profundidade 30 meses após a aplicação (Figura 3). Na camada de $0-5 \mathrm{~cm}$, observaram-se maiores valores de CTC a pH 7,0 para o calcário aplicado em superfície em relação ao incorporado, o que ocorreu possivelmente pelo maior teor de matéria orgânica do solo (Quadro 1). No entanto, parte pode ser explicada por uma provável superestimativa do valor da CTC a pH 7,0, o qual é obtido pela soma das bases trocáveis (Ca, $\mathrm{Mg}$ e K) e da acidez potencial $(\mathrm{H}+\mathrm{Al})$, graças à concentração de $\mathrm{Ca}$ e $\mathrm{Mg}$, principalmente nas parcelas que receberam calagem superficial, em que o corretivo ficou concentrado na superfície. Isto pode ser observado pelos dados de CTC a pH 7,0 da camada mais superficial do solo, seis meses após a calagem: o valor calculado para a dose $4,9 \mathrm{t} \mathrm{ha}^{-1}\left(250 \mathrm{mmol}_{\mathrm{c}} \mathrm{dm}^{-3}\right)$
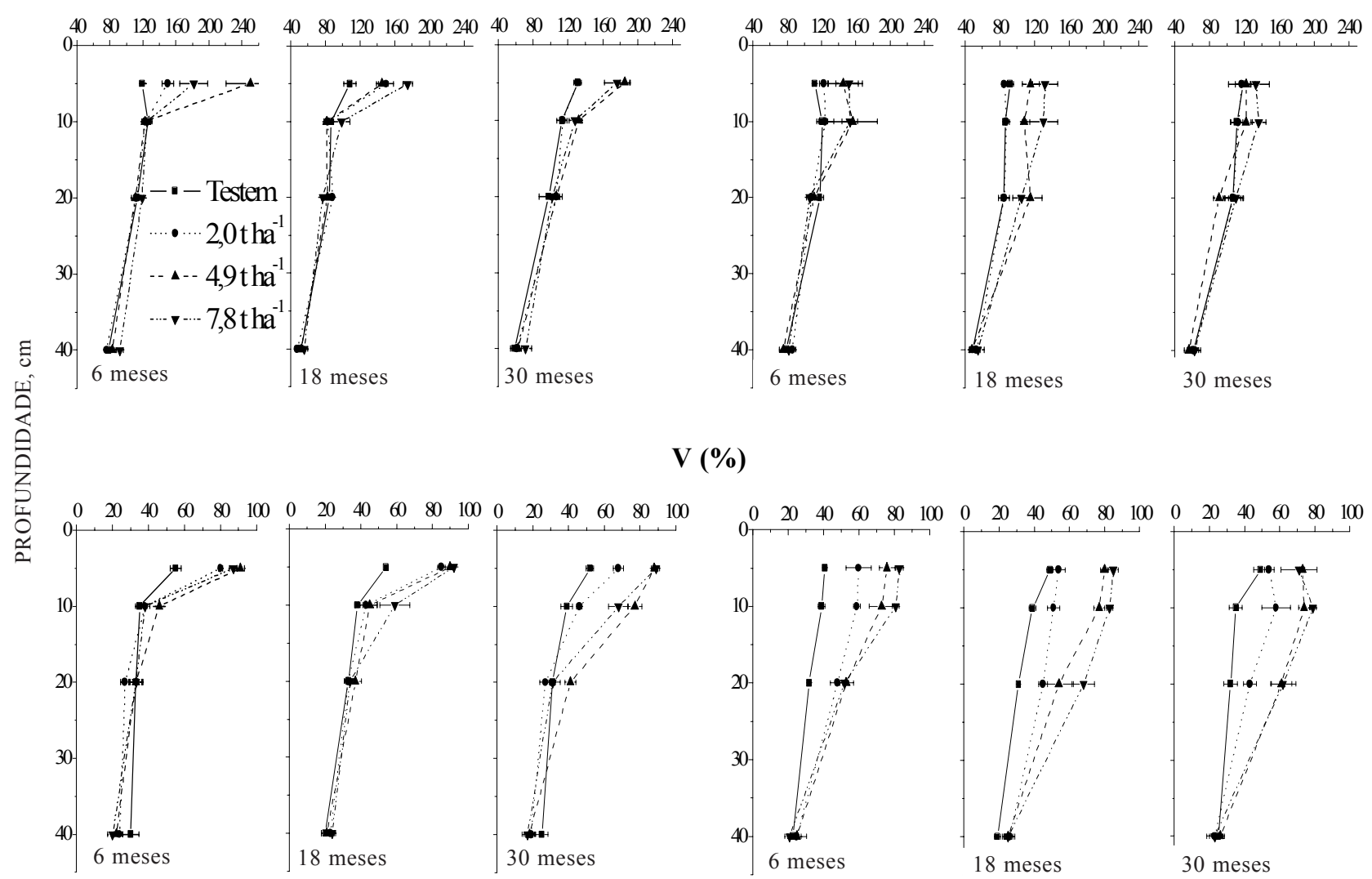

V (\%)

Figura 3. Efeito das doses de calcário, aplicado em superfície e incorporado, nos valores de CTC e saturação por bases (V) em um Latossolo Vermelho distrófico, aos seis, 18 e 30 meses da aplicação do calcário, em diferentes profundidades. (Barras horizontais referem-se ao erro-padrão das médias). 
Quadro 1. Teores de matéria orgânica em um Latossolo Vermelho distrófico, considerando as formas de aplicação do calcário (em superfície ou incorporado), aos seis, 18 e 30 meses da aplicação do corretivo

\begin{tabular}{|c|c|c|c|}
\hline \multirow{2}{*}{ Forma de aplicação } & \multicolumn{3}{|c|}{ Meses após a calagem } \\
\hline & 6 & 18 & 30 \\
\hline & \multicolumn{3}{|c|}{$\mathrm{g} \mathrm{dm}-3$} \\
\hline & \multicolumn{3}{|c|}{$0-5 \mathrm{~cm}$} \\
\hline & $52 \mathrm{a}$ & $49 \mathrm{a}$ & $55 \mathrm{a}$ \\
\hline \multirow[t]{2}{*}{ Incorporada } & $44 \mathrm{~b}$ & $43 \mathrm{~b}$ & $51 \mathrm{a}$ \\
\hline & \multicolumn{3}{|c|}{$5-10 \mathrm{~cm}$} \\
\hline Superficial & $41 \mathrm{~b}$ & $39 \mathrm{a}$ & $50 \mathrm{a}$ \\
\hline \multirow[t]{2}{*}{ Incorporada } & $42 \mathrm{a}$ & $39 \mathrm{a}$ & $47 \mathrm{a}$ \\
\hline & \multicolumn{3}{|c|}{$10-20 \mathrm{~cm}$} \\
\hline Superficial & $36 \mathrm{a}$ & $34 \mathrm{a}$ & $41 \mathrm{a}$ \\
\hline \multirow[t]{2}{*}{ Incorporada } & $38 \mathrm{a}$ & $35 \mathrm{a}$ & $42 \mathrm{a}$ \\
\hline & \multicolumn{3}{|c|}{$20-40 \mathrm{~cm}$} \\
\hline Superficial & $24 \mathrm{a}$ & $21 \mathrm{a}$ & $26 \mathrm{a}$ \\
\hline Incorporada & $24 \mathrm{a}$ & $21 \mathrm{a}$ & $24 \mathrm{a}$ \\
\hline
\end{tabular}

Letras iguais, na coluna, dentro de cada profundidade, não diferem a $5 \%$ pelo teste $\mathrm{F}$.

foi mais do que duas vezes superior ao do tratamento-testemunha $\left(119 \mathrm{mmol}_{\mathrm{c}} \mathrm{dm}^{-3}\right)$. Dessa forma, é provável que o método da determinação direta da CTC seja mais adequado para amostras de solos que receberam calcário.

Os teores de matéria orgânica (MO) não foram influenciados pelas doses de calcário, em nenhuma das três épocas estudadas, diferindo de Alleoni et al. (2003), que observaram diminuição dos teores de MO com as doses de calcário aplicadas em superfície. Segundo os autores, tal fato foi atribuído à maior atividade microbiana e, assim, à maior mineralização nas parcelas com maior $\mathrm{pH}$. Por outro lado, houve efeito do modo de aplicação do calcário (Quadro 1). Os teores de MO foram maiores na camada de $0-$ $5 \mathrm{~cm}$ com a calagem em superfície, aos seis e 18 meses da aplicação do calcário, enquanto, na camada de 5-10 cm, o teor de MO foi maior após a incorporação do calcário, somente seis meses após a calagem. Isto deve ter ocorrido pela incorporação de resíduos vegetais em profundidade, junto com a incorporação do calcário.

Resultados semelhantes foram obtidos por Santos et al. (1995), que observaram maiores teores de MO na camada mais superficial em SPD e teores maiores de MO nas camadas mais subsuperficiais em SPC. Outra possível explicação para as diferenças nos teores de MO entre os tratamentos com calcário aplicado em superfície e incorporado é o fato de o revolvimento do solo, efetuado para a incorporação do calcário, ter aumentado a aeração e o contato entre o solo e os resíduos orgânicos da superfície, o que aumentou a mineralização da MO na camada de 0-5 cm. Trinta meses após a aplicação, não houve diferença entre os teores de MO das parcelas com calagem superficial e calagem incorporada, o que realça a recuperação da MO após sua decomposição.

Seis meses após a calagem, o efeito do calcário aplicado em superfície na saturação por bases (V) ficou restrito a $5 \mathrm{~cm}$ de profundidade, chegando até à camada de 5-10 cm aos 18 meses. Aos 30 meses da calagem superficial, não houve aumento da saturação por bases nas camadas de 10-20 e 20$40 \mathrm{~cm}$ (Figura 3). Na camada de 0-5 cm, nas três épocas de amostragem, a $\mathrm{V}$ foi maior quando o calcário foi aplicado em superfície, enquanto, nas camadas de 5-10 e 10-20 cm, a saturação por bases foi maior nas parcelas em que o calcário foi incorporado (Figura 3).

Os valores de saturação por bases na camada de 0-20 cm, obtidos pelas médias ponderadas dos valores encontrados nas camadas de 0-5, 5-10 e 10$20 \mathrm{~cm}$, nas três épocas de amostragem, foram inferiores aos estimados (Quadro 2). Apenas o tratamento com calcário incorporado, na dose de $2 \mathrm{t} \mathrm{ha} \mathrm{a}^{-1}$, atingiu a saturação por bases estimada. Estudando a resposta da cultura da soja à calagem, Quaggio et al. (1982) estimaram uma dose de $5 \mathrm{t} \mathrm{ha}^{-1}$ de calcário para que fosse atingida a saturação de 70 \%. Entretanto, uma saturação máxima de $68 \%$ somente foi obtida com aplicação de $12 \mathrm{t} \mathrm{ha}^{-1}$. Um dos motivos levantados para explicar tal efeito foi a granulometria grosseira do calcário (Quaggio et al., 1982).

Esta hipótese, entretanto, não se confirmou no trabalho de Caires \& Rosolem (1993), em que foi utilizado calcário dolomítico "filler" e, após 120 e 240 dias, os valores de saturação por bases foram menores que os calculados. Os mesmos autores verificaram que, para saturação por bases até 55 a $60 \%$, os resultados encontravam-se próximos aos valores teóricos, mas, acima desses valores, havia grande diferença nos resultados, indicando que o poder tampão do solo era maior do que o estimado. Considerando a diferença entre a saturação por bases determinada e estimada, Oliveira et al. (1997) recomendaram um índice estimado de $90 \%$ de saturação por bases para calagem para milho cultivado em sistema convencional de preparo. Mello et al. (2003) não observaram diferenças nos valores de $\mathrm{pH}$ e $\mathrm{H}+\mathrm{Al}$ e nos teores de $\mathrm{Ca}$ e $\mathrm{Mg}$ de solos, quando comparados dois calcários com PRNT de $56 \%$ (granulometria grosseira) e de $90 \%$ (granulometria fina), utilizando para cada um a dose requerida para atingir a saturação por bases de $70 \%$. Esse efeito foi mantido por períodos de um, três e 12 meses após a aplicação do calcário, o que demonstra que calcários mais reativos não corrigem mais eficientemente a acidez dos solos em SPD em relação aos de granulometria mais grosseira, desde que sejam mantidas as doses requeridas. 
Quadro 2. Valores de saturação por bases (V), na camada de 0-20 cm, considerando as doses de calcário aplicado em superfície ou incorporado em Latossolo Vermelho distrófico

\begin{tabular}{|c|c|c|c|c|c|c|c|}
\hline \multirow{3}{*}{ Dose de calcário } & \multirow{3}{*}{ V estimada } & \multicolumn{6}{|c|}{ V observada $a^{(1)}$} \\
\hline & & \multicolumn{3}{|c|}{ Calcário em superfície } & \multicolumn{3}{|c|}{ Calcário incorporado } \\
\hline & & 6 & 18 & 30 & 6 & 18 & 30 \\
\hline $\mathrm{t} \mathrm{ha}^{-1}$ & & \multicolumn{3}{|c|}{$-\%$} & & & - \\
\hline 0,0 & - & 36 & 40 & 38 & 36 & 37 & 37 \\
\hline 2,0 & 50 & 43 & 48 & 42 & 54 & 49 & 49 \\
\hline 4,9 & 70 & 49 & 52 & 65 & 65 & 66 & 67 \\
\hline 7,8 & 90 & 49 & 55 & 55 & 67 & 76 & 68 \\
\hline
\end{tabular}

(1) Média ponderada da saturação por bases calculada nas camadas de $0-5 ; 5-10$ e $10-20 \mathrm{~cm}$.

Não houve efeito de doses e modos de aplicação de calcário nos teores de fósforo disponível no solo. Os teores médios de $\mathrm{P}$, das três épocas de amostragem, obtidos nas profundidades de $0-5,5-$ 10 e $10-20 \mathrm{~cm}$, foram, respectivamente, de 63,51 e $19 \mathrm{mg} \mathrm{dm}^{-3}$, quando o calcário foi aplicado na superfície, e de 49,47 e $24 \mathrm{mg} \mathrm{dm}^{-3}$, quando o calcário foi incorporado. Os teores de $\mathrm{S}-\mathrm{SO}_{4}{ }^{2-}$ no solo não foram influenciados pelas doses de calcário; entretanto, houve diferença quanto ao modo de aplicação do corretivo (Quadro 3). Na camada de 0 $5 \mathrm{~cm}$, aos seis e 18 meses da aplicação do calcário, observaram-se maiores teores de S- $\mathrm{SO}_{4}{ }^{2-}$ (com a calagem superficial). Já na camada de $5-10 \mathrm{~cm}$, aos seis meses, o teor de $\mathrm{S}-\mathrm{SO}_{4}{ }^{2-}$ foi maior com a calagem incorporada.

Como a maior parte do enxofre no solo está na forma orgânica, ligado ao carbono e ao nitrogênio do solo (Raij, 1991), este é mineralizado concomitantemente à decomposição da MO ocasionada pela incorporação do calcário ao solo (Quadro 1). Os maiores teores de $\mathrm{S}-\mathrm{SO}_{4}{ }^{2-}$ foram encontrados na camada mais subsuperficial do perfil $(20-40 \mathrm{~cm})$, o que está de acordo com os resultados obtidos por Caires et al. (1999) e com a afirmativa de que, em solos de regiões tropicais úmidas, o acúmulo de sulfatos ocorre no subsolo (Fox \& Blair, 1986).

As doses e os modos de aplicação de calcário não influenciaram os teores de $\mathrm{B}, \mathrm{Cu}$ e $\mathrm{Zn}$ no solo, nas três épocas de amostragem, tendo-se encontrado teores médios de $0,26,0,56$ e $3,12 \mathrm{mg} \mathrm{dm}^{-3}$, respectivamente, na profundidade de $0-20 \mathrm{~cm}$. A aplicação de calcário dolomítico, tanto incorporado quanto em superfície, diminuiu os teores de $\mathrm{Mn}$ (Figura 4) e de Fe no solo (Figura 5), devido ao aumento do $\mathrm{pH}$. A concentração do calcário na camada superficial do solo $(0-5 \mathrm{~cm})$ diminuiu os teores de Mn no solo nas três épocas de amostragem, enquanto esse efeito foi observado apenas aos seis meses quando houve a incorporação do calcário (Figura 4). A queda dos teores de Mn foi observada até $20 \mathrm{~cm}$ de profundidade após a incorporação do
Quadro 3. Teores de enxofre em Latossolo Vermelho distrófico, considerando as formas de aplicação do calcário (calagem em superfície e calagem incorporada), aos seis, 18 e 30 meses da aplicação do corretivo

\begin{tabular}{lccc}
\hline & \multicolumn{3}{c}{ Meses após a calagem } \\
\cline { 2 - 3 } Forma de aplicação & $\mathbf{6}$ & $\mathbf{1 8}$ & $\mathbf{3 0}$ \\
& \multicolumn{3}{c}{$\mathrm{g} \mathrm{dm}^{-3}$} \\
\cline { 2 - 4 } & $18 \mathrm{a}$ & $22 \mathrm{a}$ & $16 \mathrm{a}$ \\
& $16 \mathrm{~b}$ & $19 \mathrm{~b}$ & $13 \mathrm{a}$ \\
Superficial & $11 \mathrm{~b}$ & $5-10 \mathrm{~cm}$ \\
Incorporada & $14 \mathrm{a}$ & $21 \mathrm{a}$ & $12 \mathrm{a}$ \\
& & $10-20 \mathrm{~cm}$ & $12 \mathrm{a}$ \\
Superficial & $10 \mathrm{~b}$ & $25 \mathrm{~b}$ & $11 \mathrm{a}$ \\
Incorporada & $12 \mathrm{a}$ & $27 \mathrm{a}$ & $9 \mathrm{a}$ \\
& & $20-40 \mathrm{~cm}$ & \\
Superficial & $25 \mathrm{a}$ & $48 \mathrm{a}$ & $30 \mathrm{a}$ \\
Incorporada & $28 \mathrm{a}$ & $46 \mathrm{a}$ & $34 \mathrm{a}$ \\
& &
\end{tabular}

$\overline{\text { Letras iguais, na coluna, dentro de cada profundidade, não dife- }}$ rem a $5 \%$ pelo teste $\mathrm{F}$.

calcário, e até $10 \mathrm{~cm}$ com a calagem superficial. No tratamento com calcário em superfície, houve correlação negativa entre o $\mathrm{pH}$ em $\mathrm{CaCl}_{2}$ e os teores de $\mathrm{Mn}$ e de $\mathrm{Fe}$ no solo apenas nas camadas mais superficiais, enquanto, no calcário incorporado, esse efeito ocorreu até $20 \mathrm{~cm}$ (Quadro 4). Mesmo a dose mais alta de calcário aplicada em superfície não promoveu queda nos teores dos micronutrientes abaixo dos limites de teores no solo considerados baixos (Embrapa, 2002).

Apesar de o pH influenciar a disponibilidade de micronutrientes catiônicos no solo, nas parcelas que apresentaram maiores valores de $\mathrm{pH}$ (calcário em superfície), os teores de Mn e Fe foram maiores do que os das parcelas com calcário incorporado. Com 


\section{Calcário em Superfície}
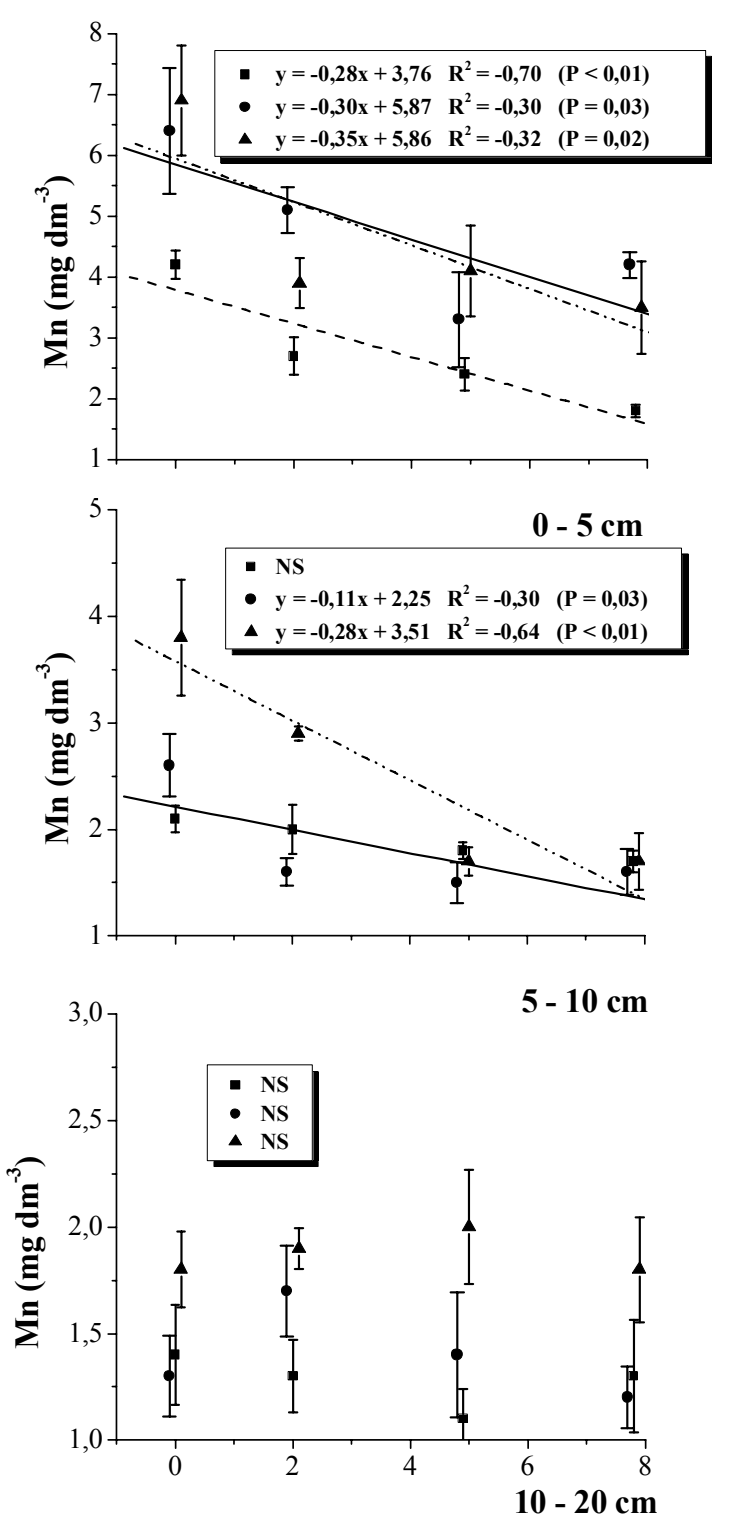

Calcário Incorporado
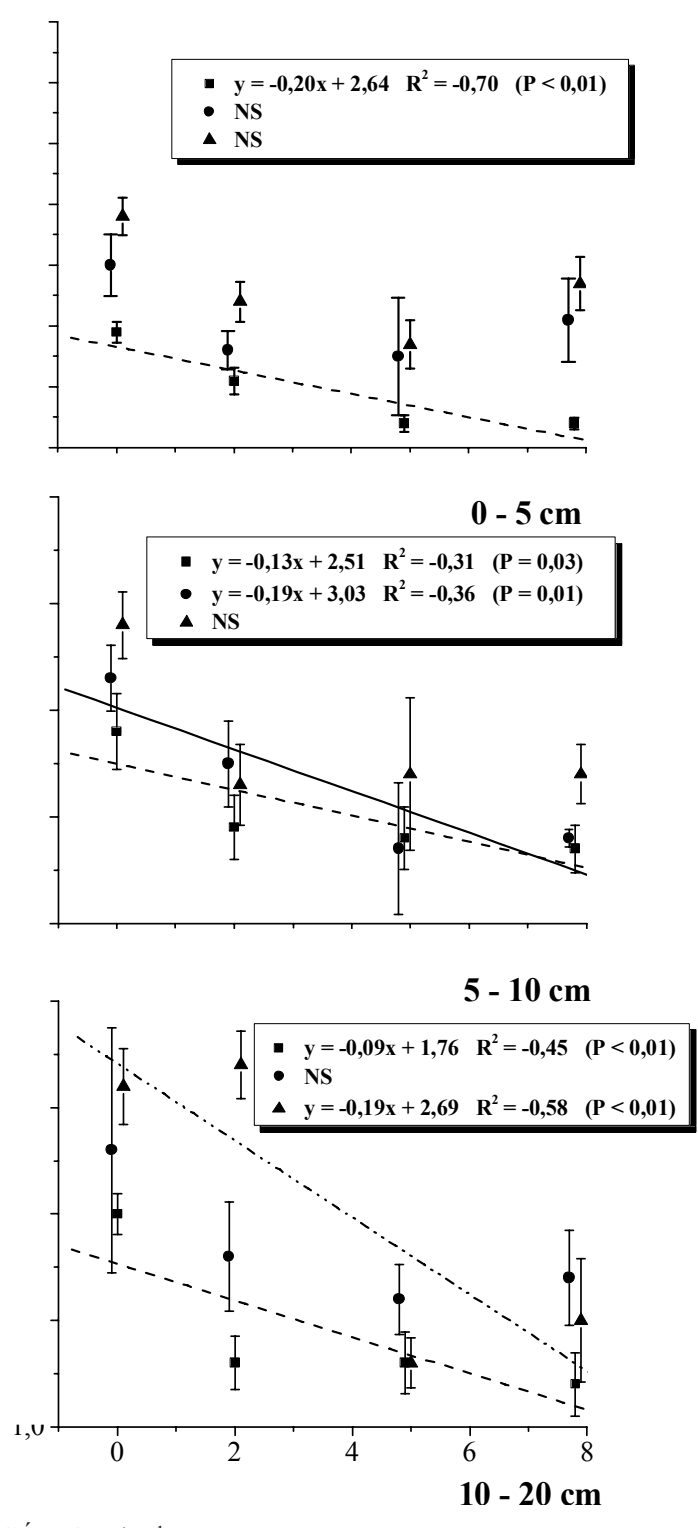

DOSE DE CALCÁRIO, $\mathrm{t}$ ha $\mathrm{a}^{-1}$

Figura 4. Teores de Mn em Latossolo Vermelho distrófico, considerando as doses de calcário, aplicado em superfície e incorporado, em três épocas e três profundidades de amostragem. Barras verticais representam o erro-padrão dentro de cada época de amostragem. $\left(\cdot=\right.$ seis meses; $\bullet=18$ meses e $\_=$ 30 meses após a aplicação do calcário). (NS = não-significativo).

o revolvimento do solo para incorporar o calcário, pode ter havido homogeneização dos teores desses micronutrientes em profundidade. Com a ausência de revolvimento do solo no SPD, aliada ao acúmulo de resíduos vegetais na superfície, ocorre maior concentração desses nutrientes nas camadas mais superficiais do solo. Em um Latossolo Vermelho perférrico de Goiás, Silveira \& Cunha (2002) observaram valores maiores de $\mathrm{Cu}, \mathrm{Mn}$ e B em SPD em relação ao sistema de preparo com arado de aiveca e sistema de preparo com grade aradora.
Não houve correlação entre os teores dos micronutrientes e da MO no solo nas diferentes profundidades de amostragem (Quadro 4). As variações nos teores de MO do solo entre os tratamentos pode ter sido muito pequena a ponto de interferir na disponibilidade do Mn e do Fe. Correlações positivas entre teores de MO e de micronutrientes foram obtidos por Castro et al. (1992), em Latossolos paulistas, para Zn, Mn e Fe; e para Zn e Mn, por Edwards et al. (1992) e Motta et al. (2002), em solos americanos. 

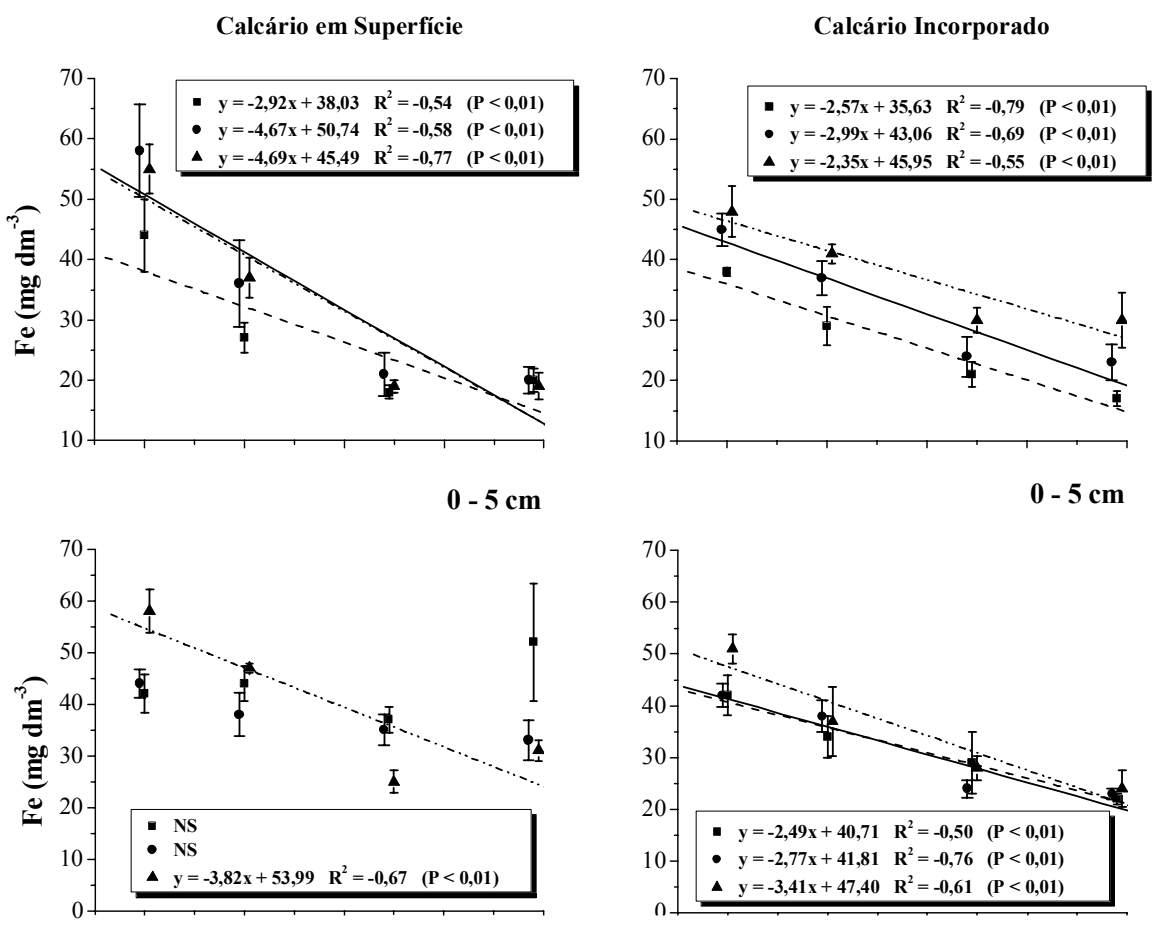

$5-10 \mathrm{~cm}$

$5-10 \mathrm{~cm}$
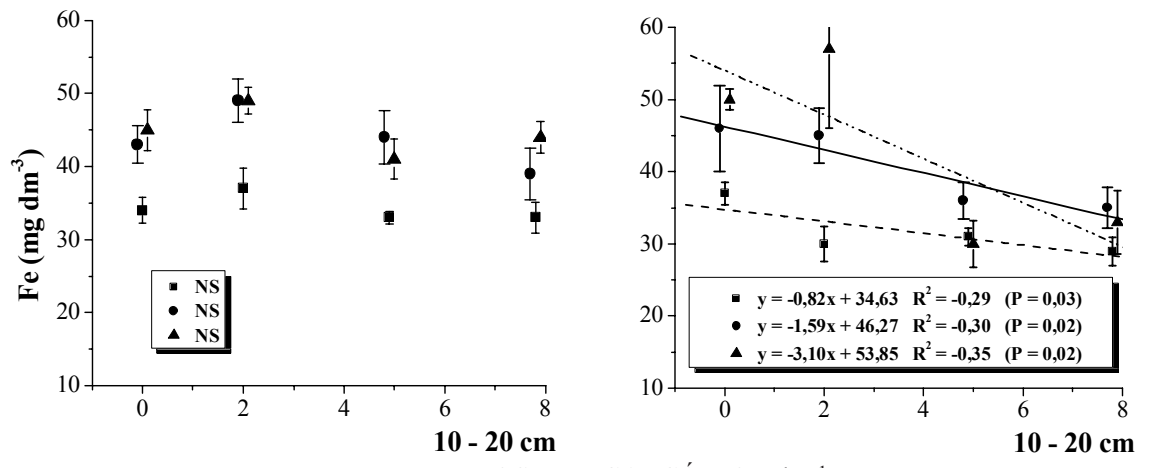

DOSE DE CALCÁRIO, $\mathrm{t}_{\text {ha }}{ }^{-1}$

Figura 5. Teores de Fe em Latossolo Vermelho distrófico, considerando as doses de calcário, aplicado em superfície e incorporado, em três épocas e três profundidades de amostragem. Barras verticais representam o erro-padrão dentro de cada época de amostragem. $\left(\cdot=\right.$ seis meses; $\bullet=18$ meses e $\_=$ 30 meses após a aplicação do calcário). (NS = não-significativo).

Quadro 4. Coeficientes de correlação (r) entre os valores de pH e teores de MO e os teores de Mn e Fe em Latossolo Vermelho distrófico, nas diferentes profundidades, aos seis, 18 e 30 meses da aplicação do calcário em superfície ou incorporado

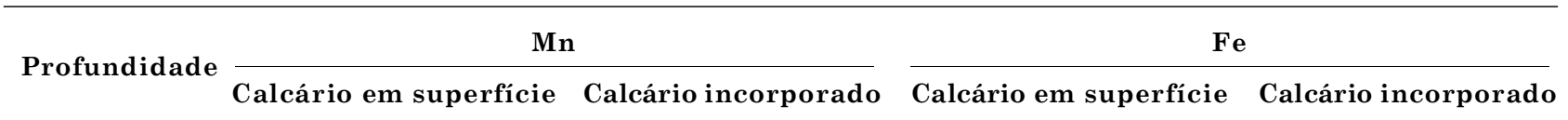

\begin{tabular}{|c|c|c|c|c|}
\hline \multicolumn{5}{|c|}{$\mathrm{pH} \times$ teor do micronutriente no solo } \\
\hline $0-5$ & $-0,71^{*}$ & $-0,70 *$ & $-0,94 * *$ & $-0,94 * *$ \\
\hline $5-10$ & $-0,40$ & $-0,76 * *$ & $-0,77 * *$ & $-0,92 * *$ \\
\hline $10-20$ & 0,43 & $-0,75^{*}$ & $-0,10$ & $-0,69 *$ \\
\hline \multicolumn{5}{|c|}{ MO x teor do micronutriente no solo } \\
\hline $0-5$ & $-0,08$ & 0,51 & $-0,14$ & 0,17 \\
\hline $5-10$ & 0,58 & 0,23 & 0,13 & 0,08 \\
\hline $10-20$ & $0,88^{* *}$ & 0,49 & 0,40 & 0,41 \\
\hline
\end{tabular}

* e $\mathrm{e}^{* *}$ : Significativos a 5 e $1 \%$. 


\section{CONCLUSÕES}

1. A neutralização da acidez do solo e o aumento do $\mathrm{Ca}$ e do $\mathrm{Mg}$ trocáveis com a aplicação de calcário na superfície restringiram-se aos primeiros $10 \mathrm{~cm}$ de profundidade, enquanto a incorporação do calcário corrigiu a acidez do solo até à profundidade de $20 \mathrm{~cm}$.

2. Os valores de saturação por bases obtidos na profundidade de $0-20 \mathrm{~cm}$ com a calagem foram menores do que os estimados pelo método da elevação da V, mesmo com a incorporação de calcário no solo.

3. A calagem reduziu os teores de Mn e Fe no solo até à profundidade de $10 \mathrm{~cm}$, quando realizada na superfície, e até à profundidade de $20 \mathrm{~cm}$, quando incorporada, mas os teores desses nutrientes mantiveram-se, ainda, acima dos limites considerados baixos.

\section{LITERATURA CITADA}

ABREU, M.F.; ABREU, C.A. \& ANDRADE, J.C. Determinação de boro em água quente, usando aquecimento com microondas. In: RAIJ, B. van; ANDRADE, J.C.; CANTARELLA, H. \& QUAGGIO, J.A., eds. Análise química para avaliação da fertilidade de solos tropicais. Campinas, Instituto Agronômico, 2001. p.231-239.

ALLEONI, L.R.F.; ZAMBROSI, F.C.B.; MOREIRA, S.G.; PROCHNOW, L.I. \& PAULETTI, V. Liming and electrochemical attributes of an Oxisol under no tillage. Sci. Agric., 60:119-123, 2003.

AMARAL, A.S. \& ANGHINONI, I. Alteração de parâmetros químicos do solo pela reaplicação superficial de calcário no sistema plantio direto. Pesq. Agropec. Bras., 36:695-702, 2001.

CAIRES, E.F. \& ROSOLEM, C.A. Calagem em genótipos de amendoim. R. Bras. Ci. Solo, 17:193-202, 1993.

CAIRES, E.F.; BANZATTO, D.A. \& FONSECA, A.F. Calagem na superfície em sistema de plantio direto. R. Bras. Ci. Solo, 24:161-169, 2000

CAIRES, E.F.; ALLEONI, L.R.F.; CAMBRI, M.A. \& BARTH, G. Surface application of lime for crop grain production under a no-till system. Agron. J., 97:791-798, 2005.

CAIRES, E.F.; CHUEIRI, W.A.; MADRUGA, E.F. \& FIGUEIREDO, A. Alterações de características químicas do solo e resposta da soja ao calcário e gesso aplicados na superfície em sistema de cultivo sem preparo do solo. R. Bras. Ci. Solo, 22:27-34, 1998.

CAIRES, E.F.; FELDHAUS, I.C.; BARTH, G. \& GARBUIO, F.J. Lime and gypsum application on the wheat crop. Sci. Agric., 59:357-364, 2002.
CAIRES, E.F.; FONSECA, A.F.; FEDLHAUS, I.C. \& BLUM, J. Crescimento radicular e nutrição da soja cultiva no sistema de plantio em resposta ao calcário e gesso na superfície. R. Bras. Ci. Solo, 25:1029-1040, 2001.

CAIRES, E.F.; FONSECA, A.F.; MENDES, J.; CHUEIRI, W.A. \& MADRUGA, E.F. Produção de milho, trigo e soja em função das alterações das características químicas do solo pela aplicação de calcário e gesso na superfície, em sistema de plantio direto. R. Bras. Ci. Solo, 23:315-327, 1999.

CAMARGO, O.A.; MONIZ, A.C.; JORGE, J.A. \& VALADARES, J.M.A.S. Métodos de análise química, mineralógica e física de solos do Instituto Agronômico de Campinas. Campinas, Instituto Agronômico, 1986. 94p. (IAC, Boletim Técnico, 106)

CARGNELUTTI FILHO, A.; REINERT, D.J. \& BORGES, D.F. Recuperação da estabilidade estrutural induzida pelo plantio direto, de solo que recebeu preparo convencional por dois anos. In: CONGRESSO LATINO-AMERICANO DE CIÊNCIA DO SOLO, 13., Águas de Lindóia, 1996. Trabalhos. Campinas, Sociedade Brasileira de Ciência do Solo, 1996. CD-ROM

CASTRO, O.M.; CAMARGO, O.A.; CANTARELLA, H.; VIEIRA, S.R. \& DECHEN, S.C.F. Teores de zinco, cobre, manganês e ferro em dois Latossolos sob plantio direto e convencional. Bragantia, 51:77-84, 1992.

CONYERS, M.K.; HEENAN, D.P.; McGHIE, W.J. \& POILE, G.P. Amelioration of acidity with time by limestone under contrasting tillage. Soil Till. Res., 72:85-94, 2003.

EDWARDS, J.H.; WOOD, C.W.; THURLOW, D.L. \& RUF, M.E. Tillage and crop rotation on fertility status of a Hapludult soil. Soil Sci. Soc. Am. J., 56:1577-1582, 1992.

EMPRESA BRASILEIRA DE PESQUISA AGROPECUÁRIA EMBRAPA. Centro Nacional de Pesquisa de Soja. Tecnologias de produção de soja: Região Central do Brasil 2003. Londrina, Embrapa-Soja/Embrapa Cerrados/ Embrapa Agropecuária Oeste, ESALQ, 2002. 199p.

FEDERAÇÃO BRASILEIRA DE PLANTIO DIRETO NA PALHA FEBRAPDP. Disponível em: <http:// www.febrapdp.org.br>. Acesso em 18 nov. 2003.

FOX, R.L. \& BLAIR, G.J. Plant response to sulfur in tropical soils. In: TABATABAI, M.A., ed. Sulfur in agriculture. Madison, American Society of Agronomy, 1986. p.405-434.

LOPES, A.S. Solos sob "cerrado": características, propriedades e manejo. Piracicaba, POTAFOS, 1984. 162p.

MELLO, J.C.A.; VILLAS BÔAS, R.L.; LIMA, E.V.; CRUSCIOL, C.A.C. \& BÜLL, L.T. Alterações nos atributos químicos de um latossolo distroférrico decorrentes da granulometria e doses de calcário em sistemas de plantio direto e convencional. R. Bras. Ci. Solo, 27:553-561, 2003.

MOTTA, A.C.; REEVES, D.W. \& TOUCHTON, J.T. Tillage intensity effects on chemical indicators of soil quality in two coastal plain soils. Comm. Soil Sci. Plant Anal., 33:913932, 2002.

OLIVEIRA, E.L. \& PAVAN, M.A. Control of acidity in no-tillage system soybean production. Soil Till. Res., 38:47-57, 1996. 
OLIVEIRA, E.L.; PARRA, M.S. \& COSTA, A. Resposta da cultura do milho, em um Latossolo Vermelho-Escuro álico, à calagem. R. Bras. Ci. Solo, 21:65-70, 1997.

PETRERE, C. \& ANGHINONI, I. Alteração de atributos químicos no perfil do solo pela calagem superficial em campo nativo. R. Bras. Ci. Solo, 25:885-895, 2001

QUAGGIO, J.A.; DECHEN, A.R. \& RAIJ, B.van. Efeitos da aplicação do calcário e gesso sobre a produção de amendoim e lixiviação de bases no solo. R. Bras. Ci. Solo, 6:189-194, 1982.

RAIJ, B. van. Fertilidade do solo e adubação. Piracicaba, Ceres, POTAFOS, 1991. 343p.

RAIJ, B. van; CANTARELLA, H.; QUAGGIO, J.A. \& FURLANI, A.M.C. Recomendações de adubação e calagem para o estado de São Paulo. 2.ed. Campinas, Instituto Agronômico/ Fundação IAC, 1996. 285p.
RHEINHEIMER, D.S.; SANTOS, E.J.S.; KAMINSKI, J.; BORTOLUZZI, E.C. \& GATIBONI, L.C. Alterações de atributos do solo pela calagem superficial e incorporada a partir de pastagem natural. R. Bras. Ci. Solo, 24:797-805, 2000.

SANTOS, H.P.; TOMM, G.O. \& LHAMBY, J.C.B. Plantio direto versus convencional: efeito na fertilidade do solo e no rendimento de grãos de culturas em rotação com cevada. $R$. Bras. Ci. Solo, 19:449-454, 1995.

SCHAEFER, C.E.G.R.; SOUZA, C.M.; VALLEJOS, M.F.S.; VIANA, J.H.M.; GALVÃO, J.C.C. \& RIBEIRO, L.M. Características da porosidade de um Argissolo VermelhoAmarelo submetido a diferentes sistemas de preparo do solo. R. Bras. Ci. Solo, 25:765-769, 2001.

SILVEIRA, P.M. \& CUNHA, A.A. Variabilidade de micronutrientes, matéria orgânica e argila de um Latossolo submetido a sistemas de preparo. Pesq. Agropec. Bras, 37:1325-1332, 2002.

VITTI, G.C. Avaliação e interpretação do enxofre no solo e na planta. Jaboticabal, FUNEP, 1989. 37p. 